joined by Joan Reynell, the psychologist, who has worked with him, both in Sheffield and at the Wolfson Centre for Developmental Paediatrics attached to The Hospital for Sick Children, Great Ormond Street. The book concentrates on the handicaps, other than defects of movement, found in children suffering from cerebral palsy, and it will be of value to trained personnel, physiotherapists, occupational and speech therapists, teachers, and other specialists, such as audiologists and orthoptists. It also makes the total problem of assessment clear to physicians especially concerned with the care of these children.

In the first section on eye defects, an account is given of normal development of vision and oculomotor control. The defects likely to be encountered in children with cerebral palsy are listed. The visuo-motor and visuoperceptual and allied difficulties are discussed, and the various means of analysing these problems. A chapter is devoted to the interpretation of these observations, and to the educational and emotional implications. The defects of hearing, speech, language, and communication are dealt with in the same way. The section on psychological testing gives an account of the problems of assessment, and the many and varied scales used. The techniques which help in the testing at each age-group are simply discussed, as well as the psychological assessment of specific disabilities.

Numerous references are given, and many explanatory case histories. There are illustrations of test situations and childrens' drawings. This book tackles the problem of the additional handicaps more fully, perhaps, than any previous similar publication. It may be of even more value to the specialist than Volume I.

\section{Practical Training for the Severely Handicapped} Child. By Milan Morgenstern, Helen LowBEER, and Franz MORgENSTERN. (Pp. 134; illustrated. 21s.) London: Spastics Society Medical Education and Information Unit in association with William Heinemann Medical Books. 1966.

This small book should find a valued place on the bookshelves of teachers, paediatricians, and parents of the physically handicapped, the mentally retarded, and the educationally subnormal children. Although it was written 30 years ago this, its first edition in English, proves that the assumptions and findings of the authors have stood the test of time. Time during which a better and wider concept of the needs of handicapped children has been steadily spreading through the civilized world. The fact that the text can be usefully read by such a large selection of interested persons, teachers, doctors, and parents might make the wary reader dubious of its value. The very fact, however, of its appeal to such a wide professional public indicates how well the authors understood the need for such a book. They set out to explain how perceptual and motor difficulties can be helped and trained towards individual improvement. The aids described are practical and illustrated clearly.

Speech and language developmental defects, too, are shown to react to "the appropriate material at the right moment' depending on the teacher's or therapist's alert recognition of the needs of the child at the time.

The apparatus described has a familiar face to modern therapists, but its value lies principally in its appeal to the imagination, stimulating new material and activity for individual needs. The teacher can gain as much as the child from this book.

Behaviour in Infancy and Early Childhood. A Book of Readings. Edited by Yvonne Brackbill and George G. Thompson. (Pp. xxi + 692; illustrated. 100s.) New York: The Free Press; London: Collier-Macmillan. 1967.

A marked feature of recent years has been the publication of many textbooks of readings in professional subjects. Usually the authors select several previously published articles and put these together with a linking commentary. The critics of this technique suggest that it is an easy way to produce a book, but this is unjustified, for with increasingly large university classes there is a real need for a careful abstraction from the vast amount of professional literature of those articles that are pertinent to the students' courses and will form a basis for their studies and subsequent reading.

This book of nearly 700 closely printed pages is arranged in eight sections each containing seven or eight selected readings. The eight sections are as follows: psychophysiological dimensions of early development; motor development and physical growth; sensory and perceptual development; conditioning and learning; from vocalization to functional language; intellectual growth; socialization and the development of social behaviour; and emotional responses and the developing personality.

Clearly, this book covers a very wide range and any selection is inevitably affected by personal bias, as shown by the fact that the selections on psychological studies are the better chosen and presented ones. Not only is there a wide range of subjects, but the readings cover a wide span of time, some being selected from writings over 50 years ago, and they represent many countries. Several of them are translations from the Russian literature, and it is particularly pleasing to have these included and made more widely available.

Most help will be obtained from this book if it is used in the way the authors intend, namely as a book for students beginning to learn about child development. During their course of instruction selected items could be referred to and reinforced by discussion and reference to other works. This latter point is particularly important because it would be unfortunate if students thought that these readings always represented the complete view on any particular subject, or even the most up-todate work on that subject, and in this respect the short lists of selected readings at the end of each article are not always as complete and representative as one would desire.

This book should be available in every paediatric library where it will be most useful to the registrars who are emerging from the confusion of preoccupation 